\title{
Legacies of Pre-Columbian land use on Latin American ecosystem composition and diversity: A case for paleoecology
}

\author{
Bronwen S. Whitney and Macarena L. Cárdenas ${ }^{2}$
}

\begin{abstract}
Impressive archaeological sites, often underlying dense forest, show evidence of past human impact within "pristine" ecosystems. Here we present four examples that highlight the challenges faced by paleoecologists in determining the potential legacies of human impact on these ecosystems.
\end{abstract}

\begin{abstract}
Across Latin America, the uncovering of impressive archaeological sites, often underlying dense forest, shows evidence of past human impact within what are often viewed as pristine ecosystems (Bush and Silman 2007; Willis et al. 2004). Anthropogenic impacts were spatially heterogeneous and it is often argued that modern floristic composition in areas of past human occupa tion espouses a legacy effect in terms of an abundance of economically useful species. Many argue that we need to shift our perceptions of what is "natural" in modern tropical ecosystems and to consider indigenous knowledge and agencies in management and conservation strategies (Clement et al. 2015). This new perspective challenges us to take into account how vegetation diversity and composition in human-impacted areas have responded and changed according to different prehistoric land-use strategies. Most studies of legacy effects rely on modern floristic surveys (Ford and Nigh 2009) that compare composition in areas inferred

emerged of higher abundance of economically important plant species, such as palms, in ancient forest gardens in Belize compared to high bush forest sites (Ross 2011). Few paleoecological studies have addressed legacy impacts on forest composition and biodiversity in the Maya lowlands, with most concerning forest clearance and agriculture at the height of the Classic Maya period. However a detailed pollen study of Lamanai, Belize, showed clear evidence of palm monoculture (Fig. 2) at the height of the Classic period (Rushton et al. 2012). Palms are vitally important plants that have a multitude of uses, including thatch, nuts, oils, and dyes. The hyperdominant occurrence of several economically important palm species across the Neotropics have been presented as evidence of their wide spread use in prehistory. However, the high palm abundance in this pollen record did not persist into the modern era. As a consequence of the reduced human manipulation of the landscape, the palm plantation rapidly reverted to a more
\end{abstract} to have experienced high and low impact in the past. A key limitation of the modern comparative approach is the lack of temporal dimension to the studies. Paleoecology can offer unique insights into legacy impacts on forest composition and biodiversity because it affords a longer temporal perspective than offered by comparative floristic studies and conventional ecology, and in most cases, the studies pre-date complex societies, so they can provide an ecological baseline. Here we review four case studies from the tropical and subtropical Americas (Fig. 1) that demonstrate how paleoecology is attempting to address the question of legacy effects on ecosystems that experienced varied prehistoric land-use strategies.

\section{Ancient Maya palm cultivation \\ Questions over the persistence of past human impacts are no better illustrated than among studies of the seasonal forests of the ancient Maya lowlands. The issue of legacy impacts in Maya forest (Lambert and Arnason 1982) initially focused on Breadnut (Brosimum alicastrum, Moraceae), an eco- nomically important tree known locally as ramón, that occurs in high proportions in forests surrounding temple ruins, but their high abundance was linked to calcareous soils created by crumbling temple ruins, rather than direct human management. More recently, convincing evidence has}

diverse seasonal broadleaf forest, suggesting that human intervention is required for monodominant palm stands to persist.

\section{The legacy of human impact} in Araucaria forest

Among the ridges of the subtropical southern Brazilian highlands, the living fossil Araucaria angustifolia tree dominates the landscapes that were once home to the complex Jê society that emerged at around 2,000 yr BP. Araucaria or the "monkey puzzle tree", provided to the Jê culture not only wood and shelter for their villages, but also one of their staple foods, the pinhão, a highly nutritious and calorie-dense nut used in their daily diet as well as in rituals and ceremonies (Iriarte et al. 2013). Paleoecological studies show that Araucaria trees arrived in the south of Brazil from about 6,000 yr BP, and expanded following the climatic trend of increased precipitation through the Holocene (Behling et al. 2004). Meanwhile, the paleoecological records within Jê archaeological 

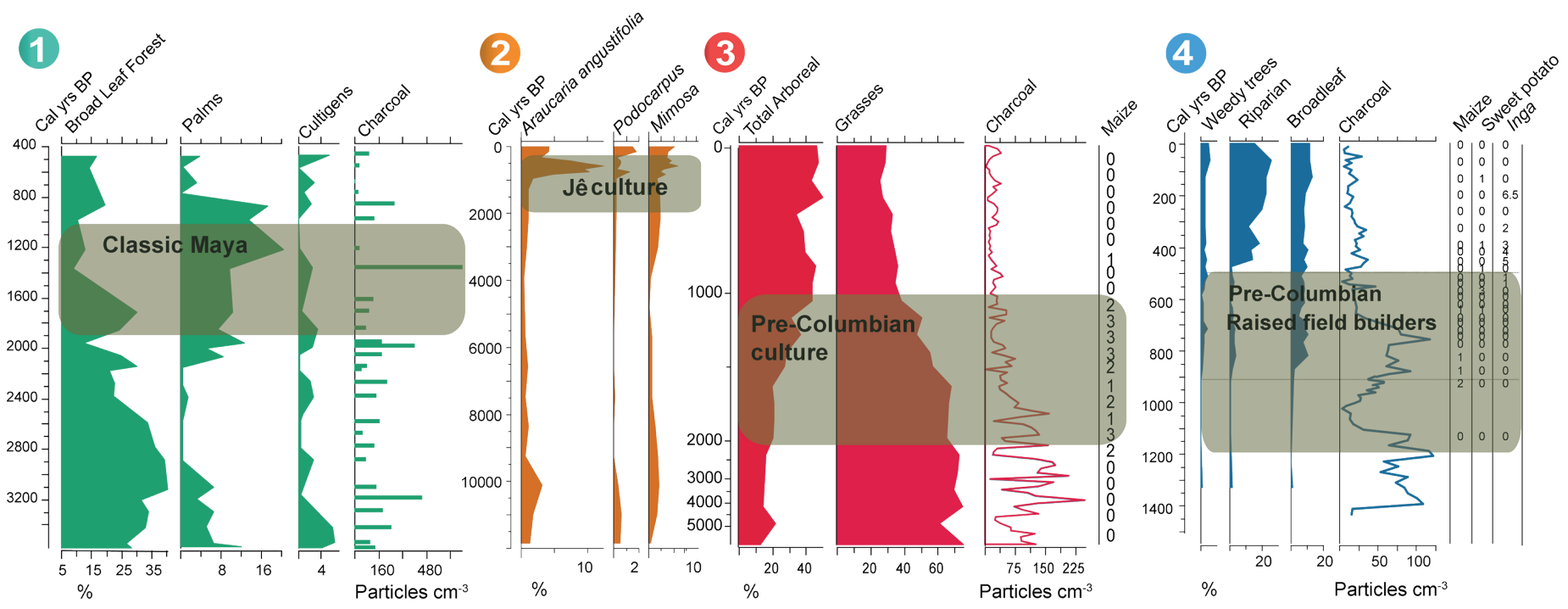

Figure 2: Selected data from the case studies showing the impact and legacy of Pre-Columbian land use on tropical ecosystems. Data are presented as percent abundance of all pollen, except in the case of large, rare pollen grains, such as Inga and maize, where individual counts are shown. (1) High palm abundance during the Classic Maya period in Lamanai (Rushton et al. 2012); (2) Very high Araucaria pollen coincides with the establishment of the Jê culture and increase in disturbance taxa (Mimosa), suggesting anthropogenic changes in the forest structure; (3) Forest expanded around the time of the establishment of "chocolate forest islands", but without evidence of Theobroma pollen in the record, we cannot determine if the high abundance of these trees occurred due to past cultivation; (4) Consistent Inga pollen after the shift from crop cultivation suggests this culture might have promoted the growth of Inga as a food source.

context shows unexpected patterns in the diversity of this forest and the abundance of Araucaria pollen if climate was the sole driving factor. The ongoing studies show that the more intense and permanent occupation of this region was associated with a regional expansion of the Araucaria forest at the same time that this culture modified the landscape at a local scale (Behling et al. 2004; Iriarte et al. 2013; Iriarte and Behling 2007). The varied proportion of Araucaria forest at human-impacted sites could reflect the legacy of pre-Columbians having facilitated the spread of this economically valuable tree species (Iriarte and Behling 2007). It is suspected that the heterogeneous local human land modification across the Jê landscape affected the diversity of "natural" vegetation (Iriarte and Behling 2007), suggesting past land-use legacies have influenced the modern vegetation.

\section{Chocolate forest islands in SW Amazonia}

Palm agroforestry by the ancient Maya may not be the only example of monodominant cultivation, as shown in the case of the "chocolate forest islands" in the Llanos de Moxos of southwestern Amazonia. The Llanos de Moxos is an Amazonian sub-basin that has been inhabited as early as $10,000 \mathrm{yr} \mathrm{BP}$, with maize crop production beginning ca. 6,500 yr BP (Brugger et al. 2016). The basin contains impermeable seasonally-flooded soils overlain by savannas; although much of the region is not hospitable for forest growth, there are forest islands on well-drained soils of outcrops of the PreCambrian Shield located within savanna. One such forest island, where a ring-ditch traces the entire periphery of the forest island, shows clear evidence of past human manipulation of the landscape (Carson et al. 2016). Intriguingly, dense stands of cacao (Theobroma cacao) occupy a large proportion of the island, which are thought to originate from either 17 th century Jesuit missionaries or Pre-Columbian agroforestry. Due to the highly-specialized pollination mechanism, however, Theobroma pollen was undetectable in the pollen record, even with counts of $>1000$ grains, so the origin of the chocolate plantation could not be dated. What paleoecology could reveal, however, is that the dense broad-leaf forests of southwestern Amazonia became established in the late Holocene $(3,000 \mathrm{yr}$ $\mathrm{BP})$ due to increasing monsoon strength, long after anthropogenic impacts had begun in this region. Given that the rainforest in this southwestern corner of Amazonia does not pre-date anthropogenic influence, composition of forest in areas adjacent to human habitation might have been influenced by people from its inception, thus the ecological baselines could be anthropogenic.

\section{Cultivation of the ice-cream bean}

Also among the lowland savannas of southwestern Amazonia, extensive Pre-Columbian raised fields show that people once cultivated these poor savanna soils where cattle ranching now predominates (Lombardo et al. 2011). Paleoecological analyses show that intensive land use began before $1700 \mathrm{yr}$ $\mathrm{BP}$, with burning and clearance of savannas and gallery forests, and raised fields were built for maize cultivation (Whitney et al. 2014). A shift towards less intensive land use incorporating sweet potato cultivation occurred around $700 \mathrm{yr} \mathrm{BP}$, and accompanying this change, Inga species colonized the riparian zones. Inga edulis is a common food resource (the ice-cream bean) and also an ecological pioneer in the establishment of secondary tropical forest. Pioneer tree species tend to out-shade themselves in the first decades following forest regeneration (Guariguata and Ostertag 2001), so its centuries-long presence in the paleoecological record points to human management of the regenerating gallery forest that stopped forest succession towards a more diverse floristic composition. The mixed strategy of agriculture and agroforestry continued until $1800 A D$, around the time land use switched to cattle ranching, suggesting that continued management was required for Inga species to persist.

This short review of Pre-Columbian impact on ecosystem composition and biodiversity shows variable evidence for legacies of past land use. The intensity and type of past management, combined with ecosystem type, might be key to controlling whether or not anthropogenic modifications create longterm changes to ecosystem composition and biodiversity. Despite having made significant inroads in redefining what is natural in tropical ecosystems, the complexity illustrated by these studies highlights the challenges ahead for paleoecology in disentangling the natural and human determinants of composition and biodiversity in tropical ecosystems.

\section{AFFILIATIONS}

'Department of Geography and Environmental Sciences, Northumbria University, NewcastleUpon-Tyne, UK

2Department of Geography and Environmental Science, University of Reading, UK

\section{CONTACT}

Bronwen Whitney: bronwen.whitney@northumbria.ac.uk

REFERENCES

Behling $\mathrm{H}$ et al. (2004) Palaeogeog Palaeoclimat Palaeoecol 203: 277-297

Brugger SO et al. (2016) Quat Sci Rev 132: 114-128 Bush MB, Silman MR (2007) Front Ecol Environ 5: 457-465

Carson JF et al. (2016) J Quat Sci 31: 337-347

Clement CR et al. (2015) Proc R Soc B 282: 20150813

Ford A, Nigh R (2009) J Ethnobiol 29: 213-236

Guariguata MR, Ostertag R (2001) Forest Ecol Manag 148 : 185-206

Iriarte J, Behling H (2007) Environ Archaeol 12: 115-127 Iriarte J et al. (2013) J Anthropol Archaeol 32: 74-96

Lambert JDH, Arnason JT (1982) Science 216: 298-299

Lombardo U et al. (2011) J Archaeol Sci 38: 502-512

Ross NJ (2011) Ecol Appl 21: 75-84

Rushton EA et al. (2012) Holocene 23: 485-493

Whitney BS et al. (2014) Holocene 24: 231-241

Willis KJ et al. (2004) Science 304: 402-403 